\title{
Implementasi Kaizen Dan 5S Pada Pengeringan Produk Di Proses Plating
}

\author{
Rahman Soesilo \\ Program Magister Teknik Industri, Pasca Sarjana, Universitas Mercu Buana \\ Jl. Meruya Sel. No. 1, Kembangan, 11650 Jakarta \\ Surel : rachman_susilo@yahoo.com
}

\begin{abstract}
Innovation can be made of small things in our routine activities. Seiri (sort), Seiton (set in order), Seiso (shine), Seiketsu (standards), and Shitsuke (sustain) is 5 words in Japanese, which is a systematic technique in correlation with efficiency. Kaizen has been widely known in the world as continuous improvement through small steps that affect the economy of the company. This system helps the management to manage the workplace, improve discipline, reduce waste and increase productivity. NGK Busi Indonesia is one of the companies owned by the Japanese spark plug that upholds the quality control contributed significantly to the implementation of Kaizen and 5S. This study explores the innovative implementation of 5S Kaizen refers to that applied in the production floor. Direct observation was made as basic methodology of this study. PT NGK Busi Indonesia always fix some work through Kaizen techniques to improve efficiency.
\end{abstract}

Keywords: 5S, efficiency, innovation, kaizen, quality

\begin{abstract}
Abstrak
Inovasi bisa dibuat dari hal kecil dalam rutinitas kita. Seiri (sort), Seiton (diatur dalam urutan), Seiso (bersinar), Seiketsu (standarisasi), dan Shitsuke (pertahankan) adalah 5 kata dalam bahasa Jepang yang merupakan teknik sistematis yang berkaitan erat dengan efisiensi. Kaizen telah dikenal secara luas di dunia sebagai perbaikan terus menerus melalui langkah-langkah kecil yang berdampak ekonomis bagi perusahaan. Sistem ini membantu manajemen mengelola tempat kerja, memperbaiki disiplin, mengurangi limbah dan meningkatkan produktivitas. NGK Busi Indonesia adalah salah satu perusahaan busi milik Jepang yang menjunjung tinggi kontrol kualitas yang berkontribusi secara signifikan terhadap pelaksanaan Kaizen dan 5S. Studi ini mengeksplorasi inovasi implementasi Kaizen yang mengacu pada 5S yang diterapkan di lantai produksi secara konkret. Pengamatan langsung dilakukan sebagai dasar metodologi penelitian ini. PT NGK Busi Indonesia selalu memperbaiki beberapa tempat kerja melalui teknik Kaizen untuk meningkatkan efisiensi.
\end{abstract}

Kata kunci: 5S, efisiensi, inovasi, kaizen, kualitas.

\section{Pendahuluan}

Kaizen adalah konsep tunggal dalam manajemen Jepang yang paling penting dan merupakan kunci sukses Jepang dalam persaingan. Jepang selalu berpikir bahwa tidak ada satu hari pun berlalu tanpa adanya suatu tindakan penyempurnaan. Kaizen merupakan alat pemersatu filsafat, system dan alat untuk memecahkan masalah yang dikembangkan di Jepang selama 30 tahun pada suatu perusahaan utnuk berbuat baik lagi. Kaizen dapat dimulai dengan menyadari bahwa setiap perusahaan mempunyai masalah. Kaizen memecahkan masalah dengan membentuk kebudayaan perusahaan di mana setiap orang dapat mengajukan masalahnya dengan bebas. 
Didalam konsep kaizen tersebut, ada salah satu konsep yang penting sebagai implementasinya, yaitu konsep 5S. Dalam beberapa tahun terakhir 5S adalah teknik yang digunakan di perusahaan Jepang untuk meningkatkan produktivitas manusia dan teknik ini diperkenalkan oleh Takashi Osada pada awal tahun 1980 [1]. Teknik 5S adalah model yang telah terbukti mengatur dan juga menjaga operasi produksi [2]. Teknik Kaizen telah dikenal di seluruh dunia sebagai metode terbaik untuk meningkatkan kinerja perusahaan karena penggunaan biaya paling rendah. Teknik ini telah dikenal untuk menyatukan karyawan perusahaan karena dapat memperbaiki komunikasi di antara mereka. Dengan melihat fenomena global, persaingan antar perusahaan sangat ketat, sehingga setiap perusahaan membutuhkan nilai uniknya. Dengan menggunakan teknik Kaizen, bisa mengubah kualitas pelayanan kepada klien. Teknik kaizen ini juga diketahui yang dapat meningkatkan perekonomian perusahaan melalui langkah-langkah kecil [3]. Secara umum, masalah utama penerapan Kaizen adalah kurangnya otorisasi dari manajemen puncak ke seluruh karyawan perusahaan. Kunci utama teknik Kaizen adalah fokus pada proses. Untuk fokus pada tujuan masing - masing divisi adalah cara termudah untuk menerapkan Kaizen dan Maka akan memperkecil risiko yang akan timbul [4]. 5S adalah salah satu konsep inovasi yang berasal dari bahasa Jepang seiri (sort), seiton (set in order), seiso (bersinar), seiketsu (standarisasi) dan shitsuke (sustained) [5]. Sebagian besar perusahaan umumnya menerapkan teknik itu untuk mengelola tempat kerja. Penerapan teknik 5S di Jepang mulai dari sektor manufaktur yang kemudian meluas ke sektor industri dan sektor jasa [6].

Teknik Kaizen telah diterapkan di PT NGK Busi Indonesia sejak awal pendirian perusahaan hingga saat ini. Teknik Kaizen diasumsikan sebagai teknik praktis dan membutuhkan biaya rendah. Implementasi teknik ini adalah pengurangan pemborosan secara kontinu. Itu tidak tergantung pada investasi tapi bergantung pada proses dan kinerja para pekerja. Untuk mendukung tujuan perusahaan dan meningkatkan keuntungan perusahaan, para pekerja menerapkan Kaizen di tempat kerja masingmasing. Kaizen telah diimplementasikan sejak perusahaan berdiri sampai sekarang dan datanya didokumentasikan setiap tahunnya. Perbaikan selalu mengacu pada teknik $5 \mathrm{~S}$ dan setiap pekerja menerapkan $5 \mathrm{~S}$ dalam pekerjaan mereka. Ini karena $5 \mathrm{~S}$ juga sudah ada dalam pikiran mereka. Teknik $5 \mathrm{~S}$ dan Kaizen ditujukan untuk latihan individual, program perbaikan jangka panjang [7]. Keuntungan hanya bisa diperoleh dari praktik berkelanjutan, hasilnya berasal dari disiplin kerja. PT. NGK Busi Indonesia selalu mengingatkan 2 teknik tersebut dalam beberapa kesempatan, seperti di pertemuan pagi dan setiap pergantian shift. Beberapa contoh Kaizen yang diimplementasikan di PT NGK Busi Indonesia yang mengacu pada teknik 5S adalah seiri (menggabungkan dua dokumen menjadi satu database), seiton (mengubah lokasi alat), seiso (mengubah bentuk lokasi limbah produksi), seiketsu (Pembuatan barkode dan warna) dan shitsuke (papan buletin mesin efisiensi).

\section{Metode Penelitian}

PT. NGK Busi Indonesia adalah perusahaan manufaktur Jepang yang didirikan di Jakarta 1980 dengan produk pertamanya adalah busi untuk sepeda motor. PT NGK Busi Indonesia dengan giat melakukan penelitian tentang teknologi fabrikasi. Akibatnya PT NGK Busi Indonesia berhasil mengembangkan bisnisnya dan memperluas pasarnya dan juga mengingatkannya akan nilai yang lebih tinggi. Untuk menjaga kinerja perusahaan, NGK Busi menerapkan teknik kaizen ke seluruh tempat kerja. 
Tujuan dari penelitian ini adalah untuk mendeskripsikan penerapan Kaizen dan 5S di PT NGK Busi Indonesia di area produksi. Perusahaan ini adalah perusahaan manufaktur Jepang, 5S dan juga Kaizen yang disukai pada umumnya digunakan di perusahaan manufaktur. Selain itu, pengendalian kualitas merupakan hal yang penting dalam bisnis di perusahaan ini terutama di bidang inovasi. Informasi yang digunakan dalam hasil akhir diperoleh dari pengamatan langsung di lapangan, bantuan pribadi dari para manajer dan pekerja, analisis data dari arsip perusahaan.. Manajer departemen pengendalian mutu dan manajer departemen sumber daya manusia adalah beberapa narasumber dalam penelitian ini.

Berikut adalah flow dari penelitian yang dilakukan pada perusahan NGK busi indonesia yang dilakukan tahap yang dapat dilihat pada Gambar 1.

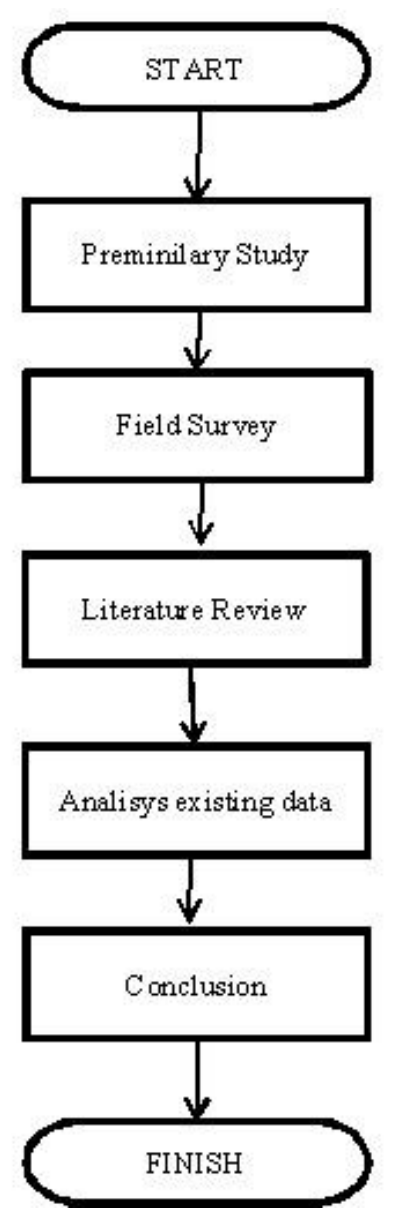

Gambar 1 Flow penelitian

Studi pendahuluan dilakukan selama 2 minggu untuk mengetahui rincian profil perusahaan dari produk yang mereka hasilkan sampai proses pembuatan produk tersebut. Studi ini dilakukan dengan pengamatan langsung terhadap situasi di pabrik dan juga menganalisis file sebelum dan sesudah implementasi Kaizen melalui inovasi 5S. Pada tahap pengumpulan data dilakukan pengumpulan data pada divisi terkait divisi kontrol kualitas, untuk melakukan perhitungan dampak biaya kepada perusahaan melalui Kaizen dan 5S. 


\section{Hasil dan Pembahasan}

Sebagian besar masyarakat umum menyamakan istilah chrome dengan semua jenis pelapisan logam. Ketika menyebutkan electroplating yang mereka maksud adalah plating. Padahal, boleh jadi pelapisan logam tersebut hanya menggunakan tembaga atau nikel saja atau gabungan keduanya, dilapis tembaga kemudian dilapis nikel, namun tidak menggunakan lapisan chrome. Chrome plating adalah salah satu teknik melapis logam (electroplating) menggunakan chromium sebagai pelapis ke permukaan logam yang hendak dilapis. Chrome adalah ungkapan populer dari Chromium yang merupakan salah satu senyawa kimia dengan symbol Cr yang memiliki nomor atom 24 (Cr 24) . Chrome adalah logam tapi dalam aplikasi penggunaannya tidak efektif dalam bentuk solid. Teknik pelapisan dasar chrome sangat bergantung pada pelapisan dasar. Untuk aplikasi decorative seperti melapis velg mobil/motor, tutup blok mesin, bumper, dan aksesoris lainnya,memerlukan pelapisan dasar menggunakan nikel plating, yakni melapis logam dengan bahan dasar nikel. Hal ini bertujuan untuk mendapatkan permukaan yang halus dan mengkilap. Nikel plating saja tidak membuat permukaan logam yang dilapis mengkilap, akan tetapi masih tampak pucat dan kekuningkuningan. Setelah dilapis dengan chrome barulah permukaan logam yang dilapis mengkilap dan bercahaya seperti pada sebuah cermin. Untuk aplikasi engineering seperti melapis silinder hidrolik, ring piston, mata bor, permukaan cetakan, tidak mesti dilapis nikel sebagai pelapisan dasar, cukup dengan memoles permukaan benda kerja sampai halus dan mengkilap lalu dilapis dengan chrome. Perbedaan mendasar antara chrome plating (untuk decorative) dan hard chrome (untuk aplikasi engineering) adalah tebal lapisan dan konsentrasi larutan chrome. Hard chrome lapisannya lebih tebal dibandingkan chrome plating biasa

Di dalam proses pembuatan busi di PT. NGK busi indonesia, ada satu part yaitu washer atau ring yang harus dilakukan proses plating atau lebih tepatnya menggunakan hard chrome. Proses plating ini berfungsi agar part yang terbuat dari besi tersebut tidak berkarat saat dipergunakan di konsumen. Pada akhir proses plating ini dilakukan pencucian atau washing, yang bertujuan agar sisa bahan kimia pada part tersebut bisa bersih. Flow proses dari plating washer ini dapat dilihat pada Gambar 2.

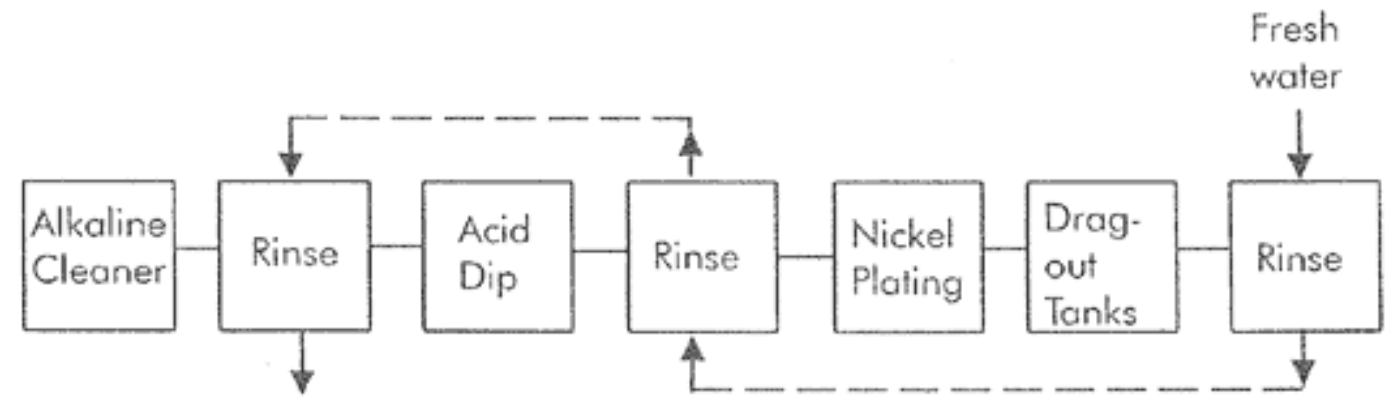

Gambar 2 Flow proses dari plating washer

Setelah proses pencucian, part yang basah tersebut harus segera dikeringkan agar sisa air menjadi bersih. Proses pengeringan air tersebut adalah dengan memasukkan dalam mesin pengering dan dilanjutkan di angin - anginkan selama $1-2$ jam dengan diletakkan di nampan yang terbuat dari box dan diletakkan di lantai produksi. Kondisi pengeringan yang diletakkan di lantai ini mengakibatkan area di produksi menjadi sempit dan juga menjadi tidak rapi. Kondisi tersebut seperti dilihat pada Gambar 3. 



Gambar 3 Kondisi area pengeringan

Melihat kondisi yang terlihat pada Gambar 3 maka di area plating ini mempunyai ide agar dapat memperbaiki kondisi tersebut diatas. Mereka melakukan tukar pikiran untuk mendapatkan ide perbaikan atau kaizen. Hasil dari ide perbaikan antara lain : mengganti tatakan box dengan plastik yang diberi lubang dan pembuatan rak untuk mengeringkan produk. Hasil perbaikan serta implementasi dari kaizen team plating dapat dilihat pada Gambar 4.
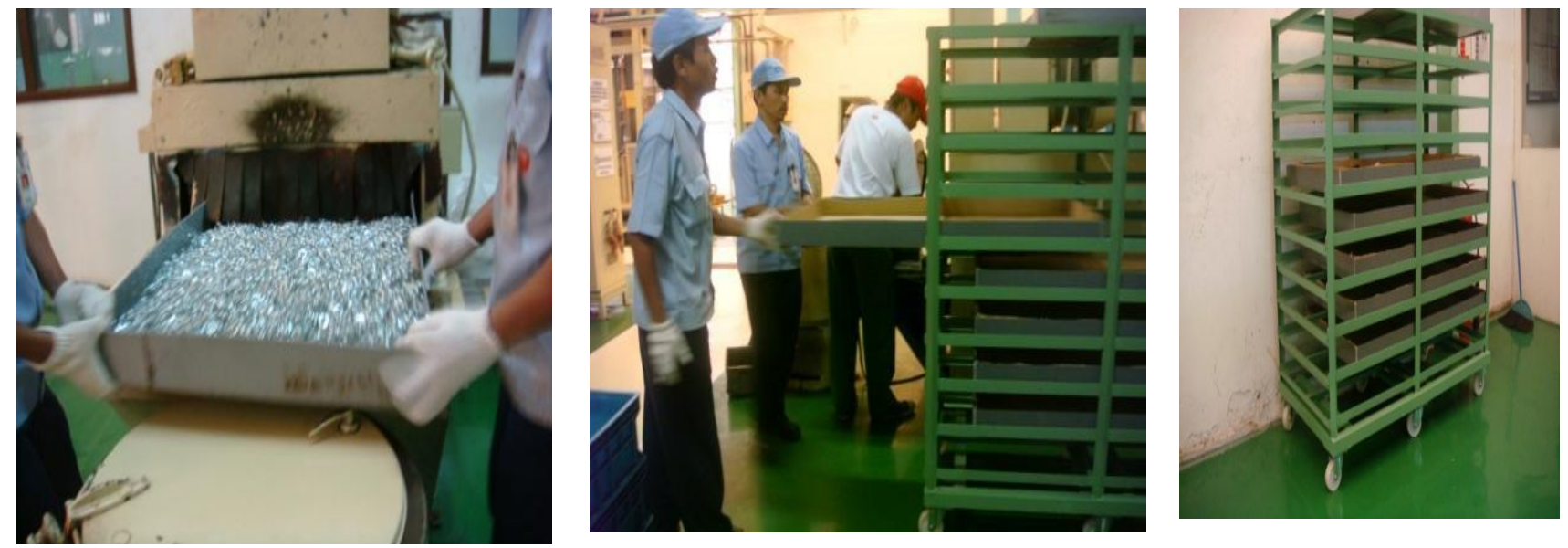

Gambar 4 Hasil perbaikan serta implementasi dari kaizen team plating

Dari implementasi kaizen untuk team plating ini dapat menghasilkan perbaikan di produksi sebagai berikut pemborosan box dapat dihilangkan, area produksi menjadi longgar dengan dibuatnya rak, peningkatan $5 \mathrm{~S}$ dari area produksi, ,meningkatkan produktifitas dari produksi

\section{Simpulan}

Penerapan konsep Kaizen dan 5S di perusahaan ini sudah berjalan cukup baik, dan ide perbaikan muncul dari produksi itu sendiri. Dengan penerapan Kaizen dan 5S, maka didapatkan hasil pengurangan pemborosan, dalam kasus ini mengurangi 
pemborosan tempat dan material. Pelaksanaan kaizen dan 5S ini harus terus ditingkatkan dan di monitor, sehingga bisa terus berkembang dan akan menjadi suatu budaya dalam perusahaan. Keuntungan dari penerapan 5S antara lain : pengurangan biaya proses dan mencegah kesalahan, utilitas tempat kerja lebih baik, efisiensi meningkat dan mengurangi waktu untuk mencari hal yang diperlukan, peningkatan keselamatan (safety), improvisasi kondisi kerja serta mempertahankan layout yang bersih dan rapi, biaya pemeliharaan mesin berkurang, peningkatan keamanan sehingga mengurangi cedera pekerja, produk rusak berkurang dikarenakan pergerakan bahan untuk proses berkurang, memberikan ruang untuk partisipasi pekerja di dalam desain area kerja dan pemeliharaan, penurunan jumlah absensi.

\section{Referensi}

[1] M. N. Ab Rahman, N. K. Khamis, R. M. Zain, B. M. Deros, and W. H. W. Mahmood, "Implementation of 5S practices in the manufacturing companies: A case study," American Journal of Applied Sciences, vol. 7, pp. 1182-1189, 2010.

[2] R. Kodama, "Medemiru Kaizen dokuhon," Nikkan Kogyo Shinbunsha, Tokyo, 1959.

[3] M. A. Titu, C. Oprean, and D. Grecu, "Applying the Kaizen method and the 5S technique in the activity of post-sale services in the knowledge-based organization," in Proceedings of the International MultiConference of Engineers and Computer Scientists, 2010, pp. 1-5.

[4] I. A. Khan, "KAIZEN: the Japanese strategy for continuous improvement," VSRD International Journal of Business \& Management Research, vol. 1, pp. 177-184, 2011.

[5] H. Chi, "1 5S implementation in Wan Cheng Industry Manufacturing Factory in Taiwan," 2011.

[6] T. Ohno, Toyota production system: beyond large-scale production: crc Press, 1988.

[7] R. Gapp, R. Fisher, and K. Kobayashi, "Implementing 5S within a Japanese context: an integrated management system," Management Decision, vol. 46, pp. 565-579, 2008. 